\title{
Efectos ambientales de la colonización española desde el río Maullín al archipiélago de Chiloé, sur de Chile
}

\author{
Environmental effects of the spanish colonization from de Maullín river to the Chiloé \\ archipelago, southern Chile
}

\author{
FERNANDO TORREJÓN ${ }^{1}$, MARCO CISTERNAS $^{2} \&$ ALBERTO ARANEDA $^{1}$ \\ ${ }^{1}$ Centro de Ciencias Ambientales EULA-Chile, Universidad de Concepción, Casilla 160-C, Concepción, Chile \\ ${ }^{2}$ Facultad de Agronomía, Universidad Católica de Valparaiso, Casilla 4-D, Quillota, Chile. \\ Autor para correspondencia: e-mail: ftorrejo@udec.cl
}

\begin{abstract}
RESUMEN
Las características biogeográficas de Chiloé limitaron la introducción y propagación de las especies animales y vegetales exóticas que sustentaban la tradicional actividad agropecuaria hispana colonial. Dicho fenómeno condicionó la ocupación y explotación económica del territorio, contribuyendo a mitigar el tipo y extensión de las alteraciones ambientales generadas por el proceso colonizador. A través de un análisis histórico documental, que abarca los siglos XVI, XVII y XVIII, en el presente trabajo se reconocen la situación ambiental prehispánica del territorio e implicancias ambientales del poblamiento colonial; el proceso de adaptación al entorno ecológico y evolución de las actividades productivas desarrolladas por los colonos. Los principales resultados obtenidos indican que no hubo transformaciones ambientales masivas y generalizadas, concluyéndose que los efectos ambientales derivados de la intervención española se evidenciaron principalmente a nivel local, pudiéndose constatar que hacia fines del siglo XVIII el paisaje ecológico de Chiloé aún conservaba muchas de sus características originales.
\end{abstract}

Palabras clave: alteraciones ambientales, ecología del paisaje, introducción de especies, colonización española, Chiloé, sur de Chile.

\begin{abstract}
The biogeographical characteristics of Chiloé limited the introduction and propagation of exotic plants and animals that supported the subsistence and economy of Spanish colonies. This in turn limited the rate of occupation and the scarce economic return of land reduced the extent and severity of environmental disturbances produced during the colonisation period. The present investigation analysed historic documentation from XVI, XVII and XVIII centuries in order to characterise pre-Hispanic environmental conditions and the environmental problems created by the colonist settlement. The adaptation of land-use practices to the region and the evolution of agricultural and forestry bring it by the colonists are described. The principal finding of this research indicates that the environmental impacts generated by the early Spanish settlement were primarily at a local level, which meant that the ecological landscape of Chiloé during the XVIII century retained several of its pristine characteristics.
\end{abstract}

Key words: environmental disturbances, landscape ecology, species introduction, Spanish settlement, Chiloé, southern Chile.

\section{INTRODUCCIÓN}

Se ha postulado que algunas de las transformaciones medioambientales más significativas generadas por el hombre en América, se originaron durante el proceso de colonización europea, siendo sus principales causas la introducción de animales domésticos y cultivos exóticos
(Roberts 1998). Sin embargo, dichos cambios, no obstante su común origen, se manifestaron y afectaron de manera distinta a diversos hábitat y ecosistemas naturales del continente; variando en extensión e intensidad de acuerdo al desarrollo de los eventos históricos, a factores étnico culturales, al potencial ecológico y las condicionantes biogeográficas del territorio (Cabrera 
1945, Cunill 1970, Prieto \& Wuilloud 1986, Chonchol 1994, Roberts 1998, Torrejón 2001).

Calificado como "llave" de los reinos de Chile y Perú, debido a su importancia estratégica, Chiloé fue el territorio más austral de América ocupado, de forma permanente, por los españoles (Olguín 1970, Guarda 1978, 1990, Urbina 1983). A partir de 1567 , y por espacio de más de 200 años, se desarrolló un ininterrumpido proceso de colonización con implicancias histórico culturales y ambientales distintas a lo ocurrido en otros espacios del actual territorio nacional (Contreras et al. 1971, Cunill 1971, Urbina 1983).

En efecto, en el centro norte de Chile y Araucanía, donde el propicio entorno natural favoreció la introducción y difusión del modelo agropecuario hispano-mediterráneo, el proceso colonizador se vio facilitado; así también, las consecuentes alteraciones del paisaje ecológico original fueron más severas y extendidas (Cunill 1970, 1971, Torrejón \& Cisternas 2002). En Chiloé, por el contrario, las características biogeográficas y aislamiento del territorio dificultaron notoriamente el poblamiento y economía colonial, obligando a los colonos a desarrollar nuevas estrategias de subsistencia basadas, en parte, en sus tradicionales actividades productivas, como así también en la asimilación de antiguos usos y técnicas de supervivencia indígenas locales (Contreras et al. 1971, Urbina 1983).

En tal sentido es posible sostener que las características climáticas, vegetacionales, la estructura y aislamiento del territorio chilote habrían condicionado la introducción de la ganadería y cultivos exóticos, determinando, a su vez, el tipo y desarrollo de las actividades económico productivas coloniales, proceso que habría atenuado las alteraciones del paisaje original. En consecuencia, en el presente trabajo se busca reconocer las transformaciones que, como resultado de la colonización española, habrían afectado al paisaje ecológico de Chiloé entre los siglos XVI y XVIII, caracterizando además el proceso de acomodación ambiental que permitió la subsistencia de los colonos en aquel territorio.

\section{MATERIALES Y MÉTODOS}

\section{Definición del área de estudio}

Considerando la evolución del poblamiento colonizador español hasta fines del s. XVIII, se definió como área de estudio el territorio de Chiloé continental e insular comprendido entre los $41^{\circ} 15^{\prime}-43^{\circ} 30^{\prime}$ S y $72^{\circ} 15^{\prime}-74^{\circ} 30^{\prime}$ O. En esta vasta extensión territorial, específicamente en el canal de Chacao y seno de Reloncaví, convergen las subzonas geográficas centro sur y Patagonia septentrional de Chile (Niemeyer 2000). Una importante superficie del área de estudio está conformada por un archipiélago de 71 islas, destacando entre ellas la Isla Grande de Chiloé, con $8.090 \mathrm{~km}^{2}$ (Niemeyer 2000). En la actualidad, el territorio en estudio forma parte de la jurisdicción político administrativa de la X Región de Los Lagos, Chile (Fig.1).

\section{Análisis bibliográfico}

Se realizó una recopilación, selección y análisis de fuentes bibliográficas coloniales, privilegiándose la documentación testimonial de primera mano, resultante de viajes de exploración geográfica y/o conquista (siglos XVI, XVII, XVIII). Complementariamente se utilizaron crónicas del siglo XVII y textos historiográficos coloniales del siglo XVIII; además de estudios geográficodescriptivos del siglo XIX, monografías y trabajos científicos de los siglos XX y XXI. Compulsadas y seleccionadas las fuentes históricas, evaluándose su procedencia, tipo de texto y calidad descriptiva del relato, se recabó toda aquella información documental que, explícita o indirectamente, hiciera referencia a la situación ambiental del área de estudio. De forma paralela, mediante diccionarios especializados (Pagés sin fecha, Moliner 1966, Corominas 1976), se precisó el uso de época de conceptos claves en la descripción del paisaje colonial. Finalmente, sobre la base de los antecedentes documentales obtenidos se efectuó una progresión histórica, procedimiento metodológico (Bolos 1992) a través del cual se fueron evidenciando las transformaciones ambientales resultantes del poblamiento colonizador hispano de Chiloé. Para ello se estableció una línea de base o descripción del estado original en que se encontraba el territorio a la llegada de los españoles (segunda mitad del siglo XVI), época a partir de la cual se inicia un registro histórico referente a la evolución de las actividades económico productivas coloniales, finalizándose con una reconstitución del paisaje ecológico del área de estudio hacia fines del siglo XVIII. 


\section{RESULTADOS Y DISCUSIÓN}

Chiloé prehispánico, las variables naturales y culturales

La interacción de variables naturales y culturales habría caracterizado el paisaje ecológico del Chiloé prehispano. Entonces, densos bosques cubrían la mayor parte del territorio definido como área de estudio, favorecidos en su desarrollo por factores climáticos de temperatura y alta pluviosidad (Villagrán 1991, Villagrán et al. 1997, Niemeyer 2000). Entre las formaciones vegetacionales más difundidas se encontraba el "bosque laurifolio de Chiloé" y "bosque siempreverde con turberas de Chiloé", de amplia cobertura tanto en el archipiélago como en el continente, existiendo también en este último espacio importantes áreas cubiertas por "bosque siempreverde andino" y "bosque siempreverde de Puyuhuapi” (Villagrán 1991, Gajardo 1994).

En un territorio donde predominaban las masas boscosas, la abundancia de recursos marinos, particularmente de mariscos, posibilitó una temprana ocupación aborigen de importantes zonas del litoral chilote. Así lo evidencian diversos yacimientos arqueológicos entre los que se encuentran conchales, corrales o cercos para captura de peces $y$, en general, sitios de
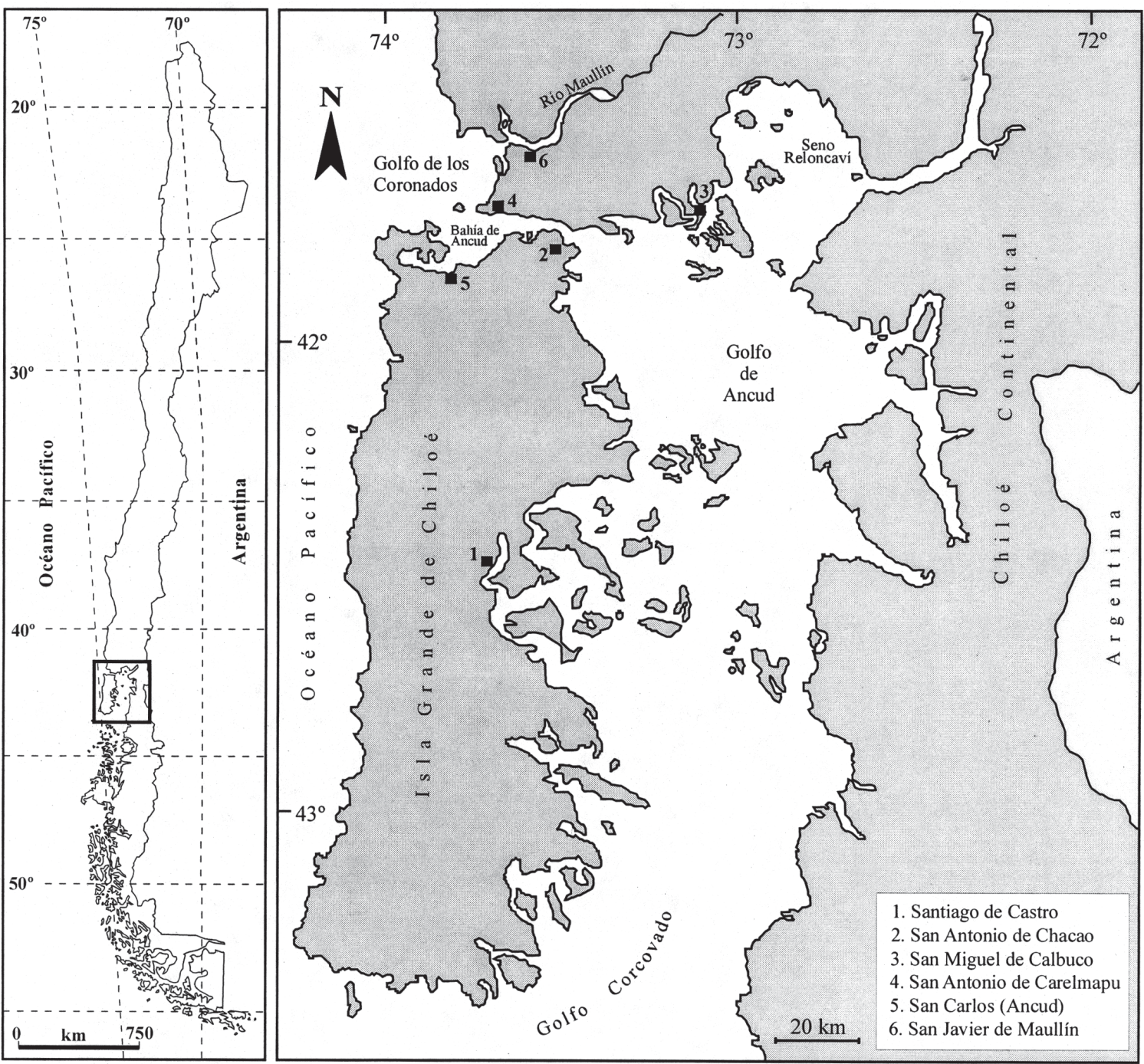

Fig. 1: Principales asentamientos coloniales de origen español en Chiloé hacia fines del siglo XVIII.

Main Spanish settlement in Chiloé late the XVIII century. 
poblamiento (Stehberg 1980). Contreras et al. (1971) sugieren que "el hábitat indígena se ceñía estrictamente a las fajas costeras de la parte oriental de la Isla Grande y de las demás islas, y en menor medida a la ribera norte del Canal de Chacao". Se trataba de un poblamiento disperso, de reducidos asentamientos familiares que no llegaban a constituir aldeas o pueblos (Dillehay 1990), estimándose que a la llegada de los españoles la población aborigen variaba entre los 50.000 y 70.000 individuos (Contreras et al. 1971).

Con probabilidad filiados étnicamente a los mapuches de la Araucanía, los pobladores indígenas de Chiloé, denominados huilliches, se habían adaptado a su entorno natural, desarrollando patrones de asentamiento y una economía de subsistencia mixta, donde se integraban distintas actividades productivas, que les permitían aprovechar adecuadamente las potencialidades ecológicas del territorio (Guevara 1925, Oyarzún 1934, Zapater 1973, Dillehay 1990).

La estrecha relación de los huilliches chilotes con el medio ambiente marino habría sido determinante en su evolución cultural. Desarrollaron un confiable tipo de embarcación denominado "dalca" (Finsterbusch 1934), que les permitía buscar y explotar los variados recursos marinos del archipiélago. Las actividades extractivas como la recolección de mariscos, la pesca y la caza de pinnípedos, e.g., Otaria byronia, eran esenciales en la economía aborigen de Chiloé (Oyarzún 1934, Ramírez 1996). Antecedentes proporcionados por Masuda (1988), permiten conjeturar que algas como el cochayuyo (Durvilaea antartica), luche rojo (Porphyra columbina) y luche verde (Ulva lactuca), fueron también aprovechadas como un antiguo recurso alimenticio indígena en Chiloé.

No obstante la importancia de las faenas extractivas vinculadas al mar, estas se habrían complementado exitosamente con labores agrícolas y ganaderas de subsistencia. En efecto, aunque ciertas variables ecológicas, como

\footnotetext{
${ }^{1}$ De acuerdo a la Real Academia Española (1989), el término "monte" en su segunda acepción significa "tierra inculta cubierta de árboles, arbustos o matas". Acepción que, como lo documentan Pagés (sin fecha) y Corominas (1961), se encontraba plenamente vigente en el castellano de la España del siglo XVI, lugar de procedencia de la mayoría de los conquistadores y colonizadores de América, donde también se difundió y conservó aquel uso y el de sus derivados (Corominas 1961, Moliner 1966).
}

la espesa cobertura vegetal, los altos índices de humedad, pluviosidad y bajas temperaturas, debieron haber dificultado las prácticas agrícolas indígenas, sobre todo aquellas basadas en la "agricultura de tala y roce" (Dillehay 1976, 1990, Aldunate 2000), existe evidencia documental que confirma la presencia de variados cultivos autóctonos en el Chiloé prehispánico. Datos proporcionados por la expedición marítima de Ladrillero (1557-1558) -previa al asentamiento de los españoles en el territorio- permiten establecer que dicha economía indígena también se sustentaba en faenas hortícolas o de agricultura básica, como se deduce de la siguiente referencia: "de esta provincia de Ancud hai grandisima fama de su fertilidad de mucha comida de maiz crecido é gran masorca papas é por otros quinoa é de tierra baja sin monte" (Gay 1852, p. 93). No obstante la elocuencia sobre la prodigalidad agrícola local, el mismo relato permite colegir que aquellos terrenos cultivables "despejados de monte"1 eran más bien escasos y circunscritos, ya que al describirse el litoral oeste, desde Carelmapu (Golfo de los Coronados) hasta el extremo sur de la Isla Grande de Chiloé, se habla de una costa poco accesible, sin puertos, donde "solo hai playas bravas, la tierra de la costa parece fea y montuosa é de mediano altor salvo junto á los dichos coronados" (Gay 1852, p. 95).

Junto a los cultivos asociados de maíz (Zea mais), quinoa (Chenopodiun quinoa) y una gran variedad de papas (Solanum tuberosum), Latcham (1936) reconoce la presencia de otras dos especies autóctonas cultivadas por los huilliches en Chiloé. Se trataba del madi (Madia sativa), oleaginosa de cuyas semillas se extraía aceite, y del cereal denominado mango o mangu (Bromus mango). La agricultura huilliche implicaba el uso de utensilios de labranza, elaborados de maderas, e.g., palo excavador, azadón, cuchillón o "hualato", con los que se preparaba eficientemente el suelo destinado a los cultivos (Oyarzún 1934, Bullock 1958). Al mismo tiempo, para fertilizar sus sembradíos, los indígenas del archipiélago parecen haber utilizado comúnmente ciertas algas marinas, e.g., lamilla (Ulva lactuca), costumbre todavía vigente en el campo chilote (Oyarzún 1934, Masuda 1988).

Otra actividad relevante en la economía prehispánica de Chiloé habría sido la crianza de 
llamas (Lama lama) u "ovejas de la tierra" como las llamaban los españoles (Thayer-Ojeda 1913, Latcham 1922, Guevara 1925). Durante el viaje de Ladrillero se describe con cierto detalle la actividad ganadera aborigen: "tienen á seis é a cuatro é a ocho obejas cada indio é á los casiques á 12 é á 15 é á 20 e sola una obeja atan é todas las otras, obeja van sueltas tras ella, no meten en casa mas de la que son lanudas las demás quedan en el prado con la que atan en un palo que tienen incado cuales tiene cada uno señaladas y el que las hurta lo mata el casique quejandose á el el que la pierde" (Gay 1852, p. 93). La relativa abundancia de ganado indígena permite deducir que la tenencia de dichos camélidos era importante en la economía doméstica aborigen, asociándose principalmente a la obtención de lana, materia prima con que los huilliches confeccionaban vestimentas adecuadas para protegerse de los rigores climáticos del territorio (Zapater 1973).

En síntesis, los aborígenes de Chiloé desarrollaron distintas actividades productivas de subsistencia, complementarias entre sí, que mantenían cierta sustentabilidad ecológica. No obstante lo anterior, Heusser (1994) y Moreno (2000) postulan la existencia de cambios vegetacionales atribuidos a fuegos generados por actividad paleoindia, desde el Pleistoceno tardío. Tales perturbaciones habrían ocurrido inicialmente a nivel local, siendo de baja severidad (Moreno 2000). Sin embargo, durante el Holoceno, particularmente después de 5.000 años AP, Heusser (1994) reconoce un notorio incremento de fuegos extensivos en el archipiélago de Chiloé. En este contexto, si bien la agricultura de tala y roce pudo haber sido una práctica agresiva contra el bosque, esta actividad parece no haber superado los límites de tolerancia y resiliencia de los ecosistemas locales (Dillehay 1976, 1990, Aldunate 2000), constituyéndose en una variable más del paisaje ecológico del Chiloé prehispánico.

\section{La percepción y valoración hispana del territo- rio}

Con la entrada de la expedición de Martín Ruiz de Gamboa a la Isla Grande de Chiloé, en el verano de 1567, comenzó la ocupación definitiva de aquel territorio. En una temprana ponderación descriptiva se indicaba: "las dichas pro- vincias de Chillué é las demás a ella comarcanas é islas, que hay gran multitud de ellas pobladas de muchos naturales, tierra útil é abundante de bastimentos de ganados ý legumbres, é donde se entiende hay mucha riqueza de metales de plata, é asimismo oro, por las buenas señales é apariencia de la tierra, donde se entiende se le seguirá a S.M. mucho interese y el patrimonio real será muy acrecentado" (Medina 1899, pp. 231-232).

Llama la atención que el observador solo destaque las características propicias para la colonización, sin hacer mención alguna al aislamiento y duras condiciones climáticas de dicho espacio geográfico, cuestión que podría interpretarse como una sobrevaloración apresurada del entorno. Sin embargo, la directa alusión a la presencia de metales preciosos, particularmente del oro, cuando ya se vislumbraba su escasez en gran parte del actual territorio de Chile ( $\mathrm{Pa}-$ checo 1991, Promis 1991), permite inferir que tan favorable evaluación territorial obedecía, más bien, a una manera de mantener el interés de la Corona en la empresa de colonización, incentivando al mismo tiempo la ocupación de estratégicos territorios periféricos, cuyas condiciones de habitabilidad eran más rigurosas.

Fomentar una economía local sustentada principalmente en la explotación del oro, era una de las intenciones primarias de los conquistadores, quienes para sostener esta actividad minera se aprovecharían de los recursos productivos y mano de obra indígena (Pacheco 1991). Pero la escasez aurífera también se haría evidente en Chiloé, defraudando a los colonos, los que, para satisfacer sus frustradas expectativas económicas, recurrirían entonces a la "exportación de naturales", situación que implicó una notoria merma de la población aborigen hacia 1600 (Contreras et al. 1971).

En pocas décadas, la optimista visión inicial del territorio habría de cambiar radicalmente. Comenzando el siglo XVII el cronista González de Nájera dejaba en evidencia el aislamiento de Chiloé y sus consecuencias. Refiriéndose la ciudad de Castro indicaba: "Está apartada de la Concepción setenta leguas. No tiene comunicación con nuestros pueblos por tierra firme [...], suelen pasarse dos o tres años que en las ciudades de tierra firme no se tiene nueva de aquel pueblo", argumentando seguidamente que el esporádico abastecimiento desde el norte hacía pasar muchas penurias a los colonos "por ser su 
isla tan estéril que no produce mas de solas las raíces que tengo dicho llaman papas, y habérseles acabado los ganados, de cuyas lanas se solían vestir" (González de Nájera 1971, pp. 8283)

\section{El impacto de los asentamientos coloniales}

Los efectos del proceso colonizador no solo recaerían sobre la población y economía indígena, pues, desde su misma llegada, los españoles contribuyeron directamente a la modificación del entorno natural de los lugares donde se asentaban. Con la ocupación hispana de Chiloé comenzaron a esbozarse transformaciones locales que paulatinamente irían alterando la fisonomía del paisaje ecológico. En el transcurso de 1567 se establecieron los primeros asentamientos españoles permanentes, el fuerte San Antonio de Chacao y la ciudad de Santiago de Castro, ambos en las costas de la Isla Grande. Más tarde, los enclaves militares de San Miguel de Calbuco y San Antonio de Ribera de Carelmapu, fundados en 1602 y 1603, respectivamente, expandieron la colonización a nuevos sectores costeros de Chiloé insular y continental (Guarda 1978, 1990).

Desde el momento mismo de su fundación dichos asentamientos habrían comenzado a generar progresivas alteraciones en los hábitat locales, afectando de manera directa la biomasa vegetal aledaña al sitio, pues durante la construcción de fuertes y poblados se usarían preponderantemente maderas del lugar. Específicamente, aquella actividad debió implicar una importante tala selectiva de árboles nativos, ya que, por ejemplo, en la construcción de las empalizadas de los fuertes de Chiloé se privilegiaba la madera de luma (Amomyrtus luma) debido a su dureza (Urbina 1983).

La tala del bosque original no solo se efectuaba mientras se erigían las edificaciones propias de tal o cual asentamiento, en la práctica esta se realizaba de forma permanente. Por una parte era necesario reparar periódicamente el deterioro sufrido por las estructuras de madera, sobre todo de las empalizadas, debido a la humedad del clima (Olguín 1970, Guarda 1990). Por otra, el vital y cotidiano uso doméstico de leña exigía un constante abastecimiento de la misma, lo que incrementaba la presión sobre la vegetación nativa. Conviene destacar aquí una interesante apreciación efectuada a fines del siglo XVIII, que caracteriza a los chilotes como grandes consumidores de leña. "Los pobladores venidos de Chiloé [...] mantienen continuamente a la usanza de aquel país el fuego en sus casas, y son capaces de consumir cuatro tantos más de leña que dichos venidos de la capital de Chile y provincias inmediatas" (O'Higgins 1942, p. 59).

A lo anterior se añadiría además la actividad del desmonte, proceso mediante el cual se despejaban totalmente parcelas de tierra, por lo general contiguas a los poblados coloniales, para destinarlas de forma sostenida a la agricultura. Primero se cortaba totalmente el bosque, dejándosele en el sitio para que se secara durante el verano, luego era quemado para que sus cenizas fertilizaran el suelo; procediéndose finalmente, en la mayoría de los casos, a la faena del "destronque" (Gay 1862, Olguín 1970, Urbina 1983). El uso agrícola dado a estos terrenos era sostenido en el tiempo, respetándose eso sí periodos de barbecho o descanso que, en Chiloé, variaban entre los 4 y 6 años, dependiendo de la fertilidad del terreno (Urbina 1983). Cunill (1971) documenta también la costumbre de "cultivar en campos permanentes", los cuales se rozaban todos los años. En esencia, el procedimiento de tala y roce utilizado por los españoles no difería mucho del empleado ancestralmente por los indígenas; sin embargo, estos últimos, no destroncaban el terreno, permitiendo así el rebrote de árboles nativos (renovales). Mas aún, tras algunas temporadas de siembras y cosechas, el sitio era abandonado (sistema de rotaciones), lo que con el pasar de los años permitía la recuperación de la cobertura boscosa (Dillehay 1990).

Estructurados para concentrar una población relativamente numerosa, los asentamientos españoles modificaron notoriamente la fisonomía del paisaje prehispánico de Chiloé, pues hasta su establecimiento, el poblamiento indígena se limitaba a pequeños núcleos familiares, asentados dispersamente en el territorio. Según el texto de la expedición de Brouwer, atribuido a Johan van Loon (Medina 1923a), en 1643 la localidad de Castro presentaba el siguiente aspecto: "Castro, entonces asolado y destruido, antes con muchos hermosos edificios, tiene una situación deliciosa, sobre un cerro alto, rodeado de hermosos árboles frutales; hay bonitos terrenos cultivados, y encontramos aún varias se- 
menteras de cereales en el campo" (Medina 1923b, p.166). Ciertamente aquella descripción evidenciaba las transformaciones locales que había sufrido el paisaje original.

Introducción y propagación de cultivos y ganados exóticos

Aun cuando en el antes citado documento histórico no se especifican los tipos de cereales cultivados en los campos de Castro, la presencia de árboles frutales es un claro indicio de una temprana difusión local de especies exóticas. En efecto, a medida que se deterioraba el sistema productivo indígena, como resultado de la expoliación colonial, los españoles habrían comenzado a introducir de manera más sistemática sus cultivos y animales domésticos para facilitar la propia subsistencia. Sin embargo, las particulares condiciones climáticas y vegetacionales del territorio no serían del todo beneficiosas para muchos cultivos y ganados de origen hispano-mediterráneo, impidiendo su masiva propagación.

Pese a lo adverso del clima, a mediados del siglo XVII ya se habían introducido varios de aquellos cultivos en Chiloé. "La tierra es naturalmente buena y fértil, produce cebada, patatas, nabos, arvejas y habas, que se cultivan por los habitantes en gran cantidad; también trigo, pero muy poco, y lino [...]; pero todos estos vegetales son echados a tierra por los fuertes temporales (a los que este clima está muy sometido), de manera que no llegan a su total desarrollo; si se sembraran aquí simientes holandesas, es dudoso que llegaran a producir fruto alguno" (Medina 1923b, pp.184-185). Salvo las "patatas" (papas), todos los demás cultivos mencionados eran ajenos a biodiversidad original de Chiloé.

La aclimatación de frutales exóticos también fue relativa, pues si bien las condiciones de humedad, en la mayoría de los casos, favorecían el crecimiento de los árboles, los frutos no siempre alcanzaban una buena madurez debido a la falta de irradiación solar y bajas temperaturas (Gay 1862, 1865). Aun así, los colonizadores introdujeron varias de sus especies frutícolas tradicionales, aunque con magros resultados, excepto en lo concerniente al manzano, frutal que se habría aclimatado mejor a las condiciones ambientales del territorio, naturalizándose incluso (Gay
1862). "La que por razón de humedad i pocos soles no fructifica es la uva, pero suplen este defecto con varias clases de sidras que sacan de la murta i de otros frutos silvestres; pero principalmente de la manzana que abunda sobremanera. Se da también el membrillo, la ciruela, la guinda i los duraznos, que no maduran bien" (Rodríguez 1901, p. 359).

Además de los efectos del clima, se ha sugerido que la escasez y mala calidad de las frutas producidas en Chiloé se debió a un inadecuado manejo de los árboles. "Las frutas que hai son [...] membrillos, tal cual árbol de ciruelas i duraznos, una rara parra, i nogal i manzanos en abundancia; la fruta de estos últimos es, por lo común, de sustancia ríjida e insipiente, porque desde que se planta la estaca hasta la ruina del árbol no se toca a él mas que para arrancarle el fruto; supongo que esto mismo sucede con los demás, i ésta es al parecer la razon de no darse los otros mas delicados con abundancia" (Moraleda 1888, p. 209).

En relación a los animales domésticos introducidos por los colonizadores, hacia mediados del siglo XVII se reconoce la crianza de "ovejas, que tienen en gran cantidad, de las cabras, chanchos y caballos; animales vacunos hay pocos" (Medina 1923b, p. 174). La presencia de distintas especies de ungulados permite estimar que, en general, estos se habían adecuado relativamente bien a las condicionantes biogeográficas de Chiloé; sin embargo, las pequeñas e insuficientes praderas naturales existentes en aquel boscoso territorio impidieron que la ganadería local alcanzaran los grandes volúmenes de las crianzas de Chile central y la Araucanía (Cunill 1971, Urbina 1983, Torrejón \& Cisternas 2002).

La pobreza de las pasturas naturales incidía también en la condición del nuevo ganado, que suplía esta falta de forraje alimentándose de vegetales como la quila (Chusquea quila) y colihues (Chusquea coleu). "Los caballos de Chiloé no son tan robustos y corpulentos como los de Chile, por defecto de los pastos. Del ganado mayor i menor se puede decir lo mismo, i, en órden al número, el menor se lleva la preferencia. El espeso bosque que abruma a este suelo es sin duda alguna el oríjen de que el ganado no arribe a aquel grado de robustez i aumento de que es capaz. No conocen las bestias mas alimento que un arbusto silvestre que llaman coligüe" (Ribera 1897, p. 5). 
En suma, las condiciones ambientales solo permitieron desarrollar una ganadería de autoconsumo, basada principalmente en el ganado menor, que apenas satisfacía la demanda local. Sin embargo, la cría de cerdos constituyó una excepción a la norma, pues estos omnívoros introducidos prosperaron exitosamente hasta convertirse en un importante recurso para la economía colonial de Chiloé (Cunill 1971, Urbina 1983). Calificados como "colonizadores primarios' (Roberts 1998), los cerdos domésticos se establecieron particularmente bien en el nuevo entorno natural, encontrando una nutritiva fuente de alimentos en el extenso litoral marino, donde devoraban los abundantes moluscos y crustáceos que la bajamar dejaba al descubierto, además de peces varados y otras especies periódicamente arrojadas por las olas (Gay 1862, Maldonado 1897).

La introducción de nuevos cultivos y ganados no solo fue relevante para la manutención de los colonos españoles, sino también para los indígenas que incorporaron algunos de ellos a su economía doméstica. La evidencia histórica permite constatar la temprana asimilación indígena de cultivos y animales exóticos, adoptados, tal vez, considerando su mejor adaptabilidad y utilidad económica. Durante 1643, cuando muchos indígenas de Chiloé, aliados de los holandeses, abordaron los buques de estos últimos, para "librarse de la insoportable tiranía de los españoles [...]; llevaban provisiones abundantes de cebada, arvejas, habas, papas, ovejas, cerdos, etc." (Medina 1923b, pp. 182183). Entre todos los vegetales nombrados, las papas eran el único producto nativo; esto no significa que los indígenas hubiesen abandonado sus otros cultivos tradicionales, e.g., quinoa, maíz y mango. Aunque no se descarta algún grado de competencia, la incorporación de semillas exóticas en la agricultura aborigen habría incrementado la variedad de cultivos en el territorio chilote (Gay 1862, 1865).

Distinta fue la situación derivada de la introducción de animales exóticos, pues si bien esta significó un notorio aumento en la diversidad y cantidad del ganado, también ocasionó la desaparición de la única especie ganadera nativa. Probablemente, a medida que los indígenas fueron criando más cerdos y principalmente lanares, que les proveían de alimento y materia prima similar a la obtenida de las llamas, permitiéndoles satisfacer adecuadamente sus nece- sidades culturales, dicho ganado indígena fue sustituido hasta su extinción local; situación que habría concordado con lo ocurrido en el centro sur de Chile durante el mismo periodo (Guevara 1925, Torrejón \& Cisternas 2002).

En 1643 aún existían llamas en Chiloé, pero ya en aquel tiempo la presencia de lanares introducidos era comparativamente mayor; cuestión que se puede inferir de las cifras proporcionadas por los holandeses: "regresaron en la tarde a bordo sin haber encontrado ningún indígena ni español; pero trajeron muchas ovejas, entre las cuales se encontraban cinco grandes ovejas-camellos (Kameel-Schapen), con lana fina y cuello de 3 ó 4 pies de largo" (Medina 1923b, p. 163). En otras oportunidades hablan de haber capturado "más de cien ovejas y cerdos [...], los del yate trajeron a bordo, de la isla más cercana, como 60 ovejas y 16 gallinas" (Medina 1923b, pp. 166-167). No se puede precisar el momento en que se produjo la total sustitución de la llama, sin embargo, es lógico pensar que esta desigual coexistencia no perduraría por mucho tiempo. La nula referencia a tales camélidos en la posterior documentación colonial referente a Chiloé, permite conjeturar que, para inicios del siglo XVIII, estos ya habían desaparecido del mencionado territorio. Guevara (1925) señala documentadamente que, a fines del siglo XVIII, la presencia de llamas en el centro sur de Chile se reducía a un escaso número de ejemplares, criados por los indígenas de Huequén, cercanías de Angol, y San José de la Mariquina, en Valdivia.

\section{Adaptación de los colonos al medio natural, evolución de sus actividades productivas}

Tras el fracaso de aquel sistema de vida basado en la expoliación de la economía indígena, y de una inadecuada percepción ambiental, reflejada en los magros resultados que venía arrojando la introducción de la mayoría de sus cultivos y ganados, los colonos hispanos se vieron compelidos a desarrollar estrategias productivas más viable, tendientes a mejorar sus precarias condiciones de subsistencia (Contreras et al. 1971). Para lograrlo deberían reinterpretar el paisaje de Chiloé, revalorando las potencialidades económicas del territorio.

Coetáneamente a los indígenas, quienes supieron complementar sus tradicionales siembras 
incorporando algunos cultivos exóticos, los españoles fueron adoptando, en mayor o menor medida, algunos cultivos aborígenes. Hacia el 1700 , los principales productos de las sementeras coloniales eran las papas, el maíz y la cebada (Cunill 1971); situación que no implicaría abandonar cultivos que ya se habían introducido, dado su arraigo cultural. "El corto cultivo de sus tierras, solo les contribuye para lo muy preciso del sustento; y lo que mas les sufraga para esto es la cosecha de papas; pues la de trigo es tan corta que si todos comieran diariamente pan estoy en que no alcanzaría para el año"2 .

El esfuerzo e ingenio de los colonos para mantener el cultivo de sus propios cereales en circunstancias ambientales adversas era evidente: "Por causa de ser tan continuas las lluvias, y en todos tiempos no les permiten dexar las mieses sin segar hasta su perfecta y correspondiente sazon. Recógenlas sin tiempo, y para secarlas cuelgan los manojos de trigo, y cebada en unas varas al sol, y si éste falta, lo ponen dentro de las casas. Son muchos los que lo guardan en espigas, y de éstas van moliendo [...] lo que necesitan para las tortillas que hacen cocidas en el rescoldo" (González de Agüeros 1988, pp. 94-95).

Este proceso adaptativo también se vio plasmado en la asimilación de técnicas agrarias indígenas, donde el suelo destinado a siembras era preparado sin la intervención del arado de tracción animal, usándose algunas herramientas de origen nativo, característica que se mantuvo durante todo el período colonial (Gay 1862, 1865, Oyarzún 1934, Urbina 1983). La utilización de algas (e.g., lamilla) en el abono de campos y cultivos era otra práctica indígena difundida entre los colonos, sin descartarse que recurrieran además al guano de lobo marino (Maldonado 1897, Oyarzún 1934). Lo anterior, paralelamente al mejor descrito uso hispano de la majada, que consistía en fertilizar una determinada parcela mediante el guano de ovejas, haciendo pernoctar allí diariamente al rebaño durante unos tres meses antes de sembrar (Gay

\footnotetext{
2 "Manifiesto sobre la situacion, estado y circunstancias notables de la Provincia y Archipielago de Chiloe. Fr. Pedro González Agueros, Madrid, Agosto 12 de 1788". Biblioteca Americana José Toribio Medina, Fondo Manuscritos, Tomo 207, Manuscrito № 5173 (Microfilm Ms. M42), fojas $158-183$; f. 170.

3 "Manifiesto sobre la situacion, estado y circunstancias...". Op. cit., fs. 171 .
}

1865, Urbina 1983). "Para guanear y beneficiar la tierra cuidan mucho el poco ganado ovejuno que tienen, y raras veces matan para si mismo res alguna" 3 .

Probablemente lo más importante en este proceso de acomodación ambiental fue la adopción de las antiguas técnicas indígenas de recolección y pesca, mismas que contribuyeron a mejorar la precaria economía doméstica de los colonos. "Para pescar hacen cuando el mar está en total vaciante unos grandes cercos formados con estacas y entretexidos con ramas. En mar lleno quedan cubiertos con las aguas, y entra en ellos sin rezelo el pescado: vuelve luego la vaciante, y queda lo mas en seco, y así cogen á su arbitrio, y hay ocasiones que sacan de uno de estos cercos, que ellos llaman Corrales, 500 ó mas robálos. Los mariscos de concha son mas abundantes, y se conocen allí los choros, tacas, piures, locos, picos, navajuelas, ostiones, quilmagues, cangrejos, cholguas, alpancoras: todos apreciables y tanto, como que son la mayor y principal parte del alimento para aquellos pobres chilotes" (González de Agüeros 1988, pp. 70-71). No se descarta que algunos colonos españoles conocieran el uso de cercos de pesca, pues una técnica similar también era utilizada en el litoral ibérico (Maldonado 1897).

En suma, las distintas actividades productivas que fueron desarrollando los colonos españoles e hispano criollos de Chiloé, irían consolidando un sistema económico mixto, donde se habrían de complementar exitosamente prácticas recolectoras, agrícolas y ganaderas. En esencia, este sistema era muy similar al indígena tradicional, salvo por otra práctica económica asociada, consistente en la explotación mercantil del bosque nativo.

\section{La actividad comercial y la explotación made- rera del bosque nativo}

Compulsada la bibliografía es posible colegir que, para mediados del siglo XVIII, existía en Chiloé un intercambio comercial externo, más o menos afianzado, basado en el trueque, o permuta directa de bienes, que permitía a los colonos abastecerse anualmente de sal, azúcar, aguardiente, vinos, tabaco, añil, yerba del Paraguay (mate), ají, jabón, papel, paños de Quito y ropas de Castilla (Olguín 1970, Cunill 1971, Urbina 1983). 
Esos insumos y mercancías de importación se cambiaban por manufacturas, textiles y productos cárneos elaborados en el territorio: "Trabajan igualmente en labrar baúles y arcas de madera, y Tablas de Lerce que es madera muy alta y gruesa en lo que tienen establecido buen renglon de Comercio. Crian juntamente ganado de bellón y trabajan en un linaje de mantas gruesas, que llaman Bordillos [...]; y en medias de lana aunque groseras como la abotonadas, de las cuales remite copiosas cantidades [...], y cosechan el Lino y le dan el beneficio que pueden, de manera que texen ruanes aunque algo groseros para su uso, y para comercio, y buenas Tablas de Manteles [...]. De los cerdos entablan otro renglon de Comercio porque los jamones del pais son los mejores y mas apreciables en el Reyno y fuera de el razón porque expenden todos cuantos sazonan en las ocasiones de las llegadas de los Navios que [...] van al Puerto de Chacao cada año" (Amat 1928, pp. 408-410).

Si bien los derivados de la agroganadería introducida se habían constituido en un rubro importante del tráfico comercial, la madera nativa continuaba siendo el principal bien de intercambio (Tabla 1). Como lo documenta Contreras et al. (1971), su exportación se remontaba a 1641, año en que se despachó un total de 6.010 tablas de alerce (Fitzroya cupressoides) desde Chiloé.

A medida que aumentaba la demanda de maderas en el Virreinato del Perú y mercados de la Capitanía General de Chile (Smith 1949,
Contreras et al. 1971), los colonos advirtieron la importancia económico mercantil que adquirían los bosques del territorio, generándose nuevos polos de intervención. Aquella tradicional actividad extractiva, que les surtía de leña y madera para uso doméstico, se incrementaría notoriamente, intensificándose la presión sobre la biomasa vegetal original, especialmente sobre los bosques de alerce. Los "astilleros" o lugares donde se efectuaba la tala y elaboración de madera fueron aumentado, estimándose que, ya en 1700 , se habían extinguido muchos de los alerzales más accesibles, lo que extendió su explotación a partes más altas del territorio (Cunill 1971). Pero esta especie arbórea no era la única extraída con fines mercantiles, también lo eran las variedades de ciprés Austrocedrus chilensis y Pilgerodendron uviferum, el avellano (Gevuina avellana), tepa (Laurelia philippiana), radal (Lomatia hirsuta), pelu (Sophora microphilla) y la luma (Amomyrtus luma) entre otras (Moraleda 1888). No obstante lo anterior, al compararse el volumen anualmente exportado, las tablas y productos elaborados con madera de alerce sobrepasaban con creces a las demás maderas (Tabla 1).

Un interesante informe de Francisco Hurtado, gobernador de Chiloé entre 1784 y 1788, demuestra la creciente importancia del alerce en el comercio colonial: "Hablaremos solo de las tablas de alerce: para la comodidad del embarque, así en las piraguas como en los buques que despues las transportan a Lima, se han de-

TABLA 1

Volumen anual de mercancías exportadas desde Chiloé (período 1778-1782)

Annual export products from Chiloé (period 1778-1782)

Tipo de mercancía

Cantidadd

(promedio anual)

Tablas de alerce

Guiones de luma y botavaras de alerce

Luma y cuarterones de alerce

Tablas de avellano, radal, cipres y laurel

Remos

Jamones

Ponchos

Bordillos

Bacalao

100.000
3.000
700
400
100
10.000
1.000
1.000

15 (quintales)

Fuente: Ribera (1897), p. 28 
terminado del tamaño de tres varas de largo, poco mas de un palmo de ancho y una pulgada escasa de grueso [...]: son cerca de 200 mil tablas las que se extraen anualmente, y á estas debe agregarse la cantidad no indiferente que se emplean en los usos domésticos"4. Sin embargo, el mismo documento permite constatar la permanencia de grandes alerzales hacia fines del siglo XVIII; todavía más, evidencia la tala selectiva de la especie, lo que inconscientemente ayudaba a la conservación de una masa forestal, aunque esto respondiese solo a motivos mercantiles. "Imagínese pues la magestuosa vista de un bosque inmenso todo lleno de esta clase de árboles: son de la especie de los cedros: crecen muy rectos con estraordinaria sanidad y permanencia y son tan robustos y corpulentos que no es estraordinario sacar de uno de ellos 500, ó 600 tablas de la medida expresada, habiendo llegado alguna vez a 800: pero a lo menos es común no derribar los árboles que no alcancen a suministrar 200 tablas" 5 .

Aparentemente el desarrollo del comercio exportador colonial habría ayudado a impulsar la actividad agropecuaria y, sobre todo, la explotación de recursos forestales. Sin embargo, características como el aislamiento territorial, el tipo de canje (trueque directo) y principalmente el monopolio ejercido por comerciantes y armadores de Lima, impusieron serias limitaciones al tráfico mercantil, perjudicando la articulación de un fluido comercio exterior que fomentara el progreso económico de Chiloé (Olguín 1970, Urbina 1983).

Pero serían dichas limitaciones las que colaboraron a mitigar las transformaciones ambientales generadas por la actividad económica colonial, pues al impedir que el volumen de productos exportados aumentara, habrían contribuido a regular el crecimiento agropecuario $\mathrm{y}$, fundamentalmente, la tala maderera, favoreciendo la conservación de muchos hábitat naturales y ecosistemas del territorio. Es así como parte de los bosques originales de Chiloé continental, y en menor medida los de Chiloé insular, incluidos antiguos alerzales, permanecieron poco intervenidos o relativamente

\footnotetext{
4 "Descripcion y noticia de las dos naciones Patagónica y Guaigüene, Isla de Chiloe". Biblioteca Americana José Toribio Medina, Fondo Manuscritos, Tomo 257, Manuscrito № 7454 (Microfilm Ms. M59), fojas 59-81; f. 78. ${ }^{5}$ Ibíd.
}

prístinos hasta fines del siglo XIX, al menos en lugares aislados o de difícil accesibilidad (Vidal-Gormaz 1871, 1875, Maldonado 1897, Elizalde 1970, Ramírez 1996).

Situación ambiental del territorio a fines del siglo XVIII

Durante la segunda mitad del siglo XVIII se establecieron formalmente nuevos asentamientos coloniales en la jurisdicción de Chiloé, el fuerte continental San Javier de Maullín (1763), en el estuario del río Maullín, y la ciudad costera de San Carlos (1768-1969), en Ancud, Isla Grande de Chiloé. Al igual que lo sucedido con fundaciones anteriores, aquellos núcleos poblados se constituyeron en nuevos focos de intervención local. "El pueblo de San Cárlos compuesto de unas 200 casas de madera cubiertas de yerba; una porcion agrupadas en una rambla junto al desembarcadero cubierto de canoas y piraguas varadas, y la mayor parte de las demás esparcidas en 20 lomas á una y otra parte, todas con sus cercas de estacada, varias con pequeños huertos. Estos objetos campean en el desmonte que se á hecho a la Isla que manifiestan la multitud de troncos pelados de árboles"6.

Como se ha señalado, los asentamientos permanentes ejercían un progresivo impacto sobre el hábitat original, incrementando los espacios alterados; sin embargo, las mismas características biogeográficas que condicionaban la explotación económica de Chiloé, también influyeron en su ocupación, contribuyendo directamente a preservar el paisaje natural de extensas áreas. En efecto, el poblamiento colonial de Chiloé insular y continental, en su mayor parte rural de tipo disperso, se redujo prácticamente a zonas costeras, donde se conformó un hábitat predial que comprendía el mar, la playa y el campo inmediatamente circundante, que luego de ser despejado era destinado a chacras y pastoreo del ganado (Urbina 1983). Incluso en poblados formales se tendía a desperdigar más las viviendas: "El pueblo de Chacao [...] se compone de unas 40 casas esparcidas que ocupan una grande estension de terreno, las acompañan ya

\footnotetext{
6 "Descripcion de la Isla San Carlos de Chiloé". Biblioteca Americana José Toribio Medina, Fondo Manuscritos, Tomo 257, Manuscrito № 7463 (Microfilm Ms. M59), fojas $188-205$; f. 190.
} 
árboles, ya pequeños huertos en que siembra cada uno la precisa cosecha de papas, quinoa que necesita para el año"7.

En 1789, refiriéndose a la Isla Grande, Moraleda decía que las gentes habitaban "dispersas la campaña, en las casas, en distancia una de otra de media milla, una, dos y algunas mucho mas [...], y tan vecinas a la orilla del mar que no hai veinte y cinco que se internen media legua. A esta situacion les obliga a los dueños su pereza e indijencia, pues una y otra son tales, que me parece imposible pudiesen subsistir sin el ausilio que incesantemente les ofrecen las playas con la portentosa abundancia de mariscos de varias clases que producen, y al mismo tiempo muy difícil que por sí mismos puedan avenirse jamás a morar desviados de ellas en lo interior de la isla" (Moraleda 1888, pp. 204-205).

$\mathrm{Si}$ bien el observador reconoce un poblamiento costero disperso, lo atribuye directamente a factores culturales subjetivos y a carencias inmediatas de los colonos (pereza e indigencia), sin percatarse que la elección del hábitat era el resultado de un complejo proceso de acomodación ambiental, donde se aprovechaban íntegramente las potencialidades de un entorno relativamente adverso. El mar, además de una abundante fuente de recursos alimenticios, era la principal vía de comunicación y comercio para los habitante de Chiloé.

Como es lógico, este mismo proceso de acomodación ambiental favoreció la permanencia de ancestrales cultivos autóctonos, los que fueron incorporados plenamente en la agricultura colonial, incluso uno de ellos predominó sobre los cultivos introducidos. En 1773 el gobernador Beranger indicaba: "la cosecha de papas es numerosa y sería abundantísima con la calidad de buenas i excelentes si se aplicaran a aumentar su trabajo i siembra [...]. Es el alimento jeneral de esta provincia porque es el pan [...]. El trigo i la cebada es mediana su cosecha, no llega a su madurez porque le falta calor del sol para lograrlo perfectamente $[\ldots]$, se siembra alguna linaza pero no con abundancia [...]. Quinoa es por buena particular i la mezclan con harina de cebada para tener chicha. El maiz, aunque se coje poco, tiene el mismo destino; zapallos porotos

${ }^{7}$ Ibíd., f. 200. i alberjas se siembran en corta cantidad; las habas abundan mas". Seguidamente el autor se contradice al señalar: "De las semillas propias del pais se han dejado casi todas, menos las papas. El magu solo ha quedado, i tal o cual lo siembran para chicha" (Beranger 1893, p. 215). La alusión a la siembra del "magu" (mango) es muy interesante, pues Chiloé, tal como lo documenta Gay (1865), parece haber sido el último territorio donde se mantuvo vigente su cultivo, desaparecido tempranamente del centro sur de Chile, sustituido por granos exóticos (Torrejón \& Cisternas 2002).

No obstante la permanencia de muchos cultivos autóctonos, la escala de estas siembras era menor al compararlas con los cultivos introducidos, salvo en lo que respecta a la tradicional papa, cuya importancia en la dieta de Chiloé hizo que su cultivo se arraigara entre los colonos hispano-criollos, constituyéndose, de acuerdo a las cifras, en la principal producción agrícola colonial (Tabla 2). Esta situación habría contribuido a la persistencia de distintas variedades de papas, algunas exclusivas de Chiloé; Gay (1865) identificó 45 clases de ellas en su paso por el archipiélago.

Como antes se ha señalado, la introducción de ungulados domésticos sustituyó al ganado indígena, constituido exclusivamente por llamas, ocasionando su temprana desaparición. Probablemente debido a una relativa escasez y al desconocimiento técnico de la crianza de camélidos, los colonos hispanos no asimilaron la crianza del ganado local, introduciendo sus propias especies, las que se irían adaptando a las condiciones ambientales del territorio. Considerando el número y tipos de ganados inventariados en el archipiélago de Chiloé en 1783 , es posible inferir que se había optado por una ganadería de pequeña escala, sustentada principalmente en la crianza de ovejas, cabras y cerdos, sin desconocer una significativa presencia de ganado mayor (Tabla 2).

Tal vez una de las transformaciones más importante del paisaje ecológico del Chiloé colonial, derivada de la introducción de especies biológicas, fue la naturalización del manzano y, en menor medida, del ganado bovino. Hacia fines del siglo XVIII se reconocía una gran proliferación ex situ del mencionado frutal: "El infinito número de manzanos silvestres que se da en aquel suelo, pone a sus habitantes en estado de hacer una sidra que, aunque im- 
perfecta, la conservan seis u ocho meses" (Ribera 1897, p. 5). Propagación que se habría dado indistintamente en Chiloé continental e insular: "El manzano, asi como en el continente es el frutal que mas abunda en esta isla" 8 . Por otra parte no se descarta que durante las inesta- bles postrimerías del periodo colonial se haya naturalizado cierta cantidad de vacunos, reproduciéndose y perdurando con algún éxito en los espacios boscosos de Chiloé continental, hasta que fueron exterminados por la caza (Philippi 1885, Vidal-Gormaz 1871).

TABLA 2

Producción y existencias agropecuarias de Chiloé en 1783

The farming production of Chiloé in 1783

\begin{tabular}{|c|c|c|}
\hline Cosechas & Volumen & \\
\hline Papas & 65.000 & fanegas \\
\hline Trigo & 17.557 & $"$ \\
\hline Cebada & 11.420 & $"$ \\
\hline Habas & 271 & $"$ \\
\hline Quinoa & 222 & $"$ \\
\hline Cebollas & 200 & $"$ \\
\hline Ajos & 160 & $"$ \\
\hline Frijoles & 152 & $"$ \\
\hline Porotos & 33 & $"$ \\
\hline Calabazas & 500 & unidades \\
\hline Repollos & 4.800 & $"$ \\
\hline Lino & 109 & arrobas \\
\hline Frutales & Número de árboles & \\
\hline Manzanos & 48.793 & \\
\hline Membrillos & 192 & \\
\hline Ganados & Número de cabezas & \\
\hline Ovejas & 86.683 & \\
\hline Carneros & 2.160 & \\
\hline Cabras & 17.307 & \\
\hline Chivos & 1.354 & \\
\hline Cerdos & 5.054 & \\
\hline Cerdas & 3.381 & \\
\hline Vacas & 3.780 & \\
\hline Toros & 1.024 & \\
\hline Yeguas & 3.525 & \\
\hline Caballos & 3.467 & \\
\hline Potros & 936 & \\
\hline Aves de corral & Número de aves & \\
\hline Gallinas & 20.740 & \\
\hline Pavos & 1.200 & \\
\hline Gansos & 800 & \\
\hline
\end{tabular}

Fuentes: "Descripcion y noticia de las dos naciones...". Op. cit., f. 81 "Copia de una descripción política de la isla...". Op. cit, fs. 16-17. Beranger (1893), p. 215

8 "Copia de una descripcion política de la isla. (Producción, comercio, costumbres). (1783?)". Archivo Nacional, Fondo Archivo Hidrográfico "Vidal-Gormaz", Volumen 14, Pieza 1, fojas 1-26; f. 17. 


\section{Composición demográfica del territorio}

La variable demográfica también había experimentado cambios notorios hacia fines del siglo XVIII (Urbina 1983), desempeñando probablemente un importante rol en la evolución ambiental de Chiloé. De acuerdo a las cifras, en 1789 vivían en aquel territorio "15072 almas de españoles, entre quienes están injeridos algunos mestizos favorecidos, i en 11617 indios, entre los cuales se incluyen tambien porcion de mestizos; 6121 de los primeros habitan en las islas contiguas a la grande, $\mathrm{i}$ el resto, 8951, en ésta $\mathrm{i}$ la tierra firme de los partidos de Calbuco y Carelmapu; de los segundos viven en dichas islas 5766 i los 5851 restantes en la isla grande i partidos dichos; de forma que el total de almas de la provincia asciende a 26689, número que parece bastante limitado" (Moraleda 1888, p. 204).

De acuerdo a los cálculos entregados por Contreras et al. (1971), se puede inferir que los habitantes indígenas de Chiloé se habían reducido ostensiblemente -de entre 50.000 a 70.000 individuos estimados al inicio de la ocupación hispana, a tan solo 11.617 en 1798-. Por otra parte, la población total registrada en 1789 correspondería tan solo a más o menos la mitad de la población aborigen que habría existido en los albores de la colonización de ese territorio. En términos cuantitativos, es muy probable que el bajo número de colonos allí asentados haya sido otro factor gravitante en la conservación del paisaje natural, compensado y mitigando en parte los efectos de su irrupción.

Al considerar que en la Isla Grande de Chiloé se concentraba prácticamente la mitad de la población total asentada en el territorio, y que su sustento dependía en gran medida del mar, los indicios históricos permiten estimar que el ecosistema marino durante el siglo XVIII aún parecía mantener su alta diversidad prehispánica: "El mar contiguo abunda de lobos marinos, ballenas, robalos, corbina y sardinas, ademas de la nutria ó gato marino que nos ha parecido igual á la nutria del Canadá" ${ }^{\text {. }}$. Otro tanto ocurría con los ecosistemas terrestres donde se describía la presencia de abundante fauna nativa, compuesta principalmente de aves: "Desde la punta Kinterkon hasta Chacao, se ven innumerables bandadas de Becacinas, Chorlitos, Zarapicos, Numenios [...]que oscurecen el aire; se

${ }^{9}$ Descripcion y noticia de las dos naciones...". Op. cit., f. 81. ven bandadas de los extraordinarios pájaros que llaman Pico tijeras"10.

No obstante las transformaciones acaecidas en el transcurso de algo más de dos siglos de ocupación colonial, gran parte del territorio de Chiloé mantenía aún muchas de sus características ambientales originales. La presencia de densos bosques nativos seguía predominando en el paisaje chilote: "y ahora diré de sus territorios lo que he visto. Estos en todo el Archipiélago son montuosos y quebrados ocupando sus fragosos y dilatados montes la mayor parte de las Islas, y dejando solamente las orillas del mar (y no en todas partes) y algunas otras llanuras en el centro de ellas" (González de Agüeros 1988, p. 83). Entonces, para quien observaba por primera vez, la percepción del territorio, no distaba mucho de la que habían tenido sus descubridores: "la Isla de Chiloe ya puerta de los españoles en el Mar Pacífico, parece mas bien por su frondosidad y arboleda casi impenetrable" 11 .

En consecuencia, de acuerdo a la evidencia histórica presentada, es posible sostener que la colonización hispana de Chiloé se vio notoriamente condicionada por las características biogeográficas del territorio, que atenuaron sus efectos ambientales, contribuyendo a la preservación del entorno natural. De hecho, tanto el poblamiento como el tipo e intensidad de las actividades económico productivas, desarrolladas durante la intervención colonial, produjeron solo transformaciones locales, no afectando regionalmente al paisaje ecológico de Chiloé, excepto en lo referido a la desaparición de la llama y a una significativa merma de la población indígena.

\section{CONCLUSIONES}

La diversificada economía aborigen prehispánica de Chiloé habría sido ecológicamente sustentable. La irrupción española significó un temprano y progresivo deterioro de la sociedad indígena; paralelamente, la fundación de asentamientos coloniales fue generando notorias alteraciones locales en el paisaje natural. Durante el siglo XVII el intento de instaurar una economía sustentada en cultivos y ganadería de ori-

\footnotetext{
${ }^{10}$ Ibíd., fs. 69-70.

${ }^{11}$ Ibíd., f. 60.
} 
gen hispano-mediterráneos se vio condicionada por el clima, vegetación, estructura y aislamiento del territorio chilote, que limitaron la propagación de los ungulados y cultivos exóticos. Excepcionalmente, algunas especies introducidas se adaptaron bien a las condiciones ambientales, siendo adoptadas por los indígenas y/ o naturalizándose. Desaparece o se extingue localmente la llama, reemplazada por el ganado menor. Los colonos hispanos reevalúan las potencialidades de su nuevo entorno geográfico, generándose un proceso de acomodación ambiental, donde se adoptaron algunos usos, técnicas y cultivos indígenas, situación que, en parte, contribuyó a mitigar los efectos ambientales de la colonización. Durante el siglo XVIII se desarrolla una limitada actividad comercial, sustentada principalmente en la explotación maderera del bosque nativo. En referencia a la actividad agropecuaria, se verifica la coexistencia de cultivos autóctonos e introducidos, predominando el cultivo de la papa. Paralelamente se desarrolla la crianza de ganado introducido, preponderando la ganadería menor. Se constatan cambios significativos en la configuración demográfica del territorio. En síntesis, si bien se reconocen importantes transformaciones locales en el paisaje ecológico de Chiloé, las mismas se vieron atenuadas por las condiciones biogeográficas del territorio, pudiéndose establecer que, a fines del siglo XVIII, gran parte de Chiloé continental e insular mantenía muchas de las características ambientales encontradas por los colonizadores, es decir, hábitat relativamente prístinos o poco intervenidos.

\section{AGRADECIMIENTOS}

Investigación financiada y desarrollada en el marco del Proyecto FONDECYT 1020224. Los autores desean agradecer a los doctores P. Oyaneder, R. Urrutia, A. Arrizaga, F. Cruces, L. Torres y P. Goodwin por sus comentarios y sugerencias.

\section{LITERATURA CITADA}

ALDUNATE C (2000) Estadio alfarero en el sur de Chile (500 a ca. 1800 d.C.). En: Hidalgo J,V Schiappacasse, H Niemeyer F, C Aldunate del Solar \& I Solimano (eds) Culturas de Chile. Prehistoria desde sus orígenes hasta los albores de la conquista: 329-348. Cuarta edición. Editorial Andrés Bello, Santiago, Chile.
AMAT M DE (1928) Historia geographica é hidrographica con derrotero general correlativo al Plan de el Reyno de Chile. Revista Chilena de Historia y Geografía 60: 394-426.

BERANGER C DE (1893) Relacion Jeográfica de la Isla de Chiloé. Anales de la Universidad de Chile 84: 181-243.

BOLÓS M DE (1992) La evolución o arqueología del paisaje. En: Bolós M de (ed) Manual de ciencia del paisaje teoría, métodos y aplicaciones: 191-203. Masson S.A., Barcelona, España.

BULLOCK D (1958) La Agricultura de los Mapuches en tiempos pre-hispánicos. Apartado del Boletín de la Sociedad de Biología de Concepción (Chile) X: 141-154.

CABRERA A (1945) Caballos de América. Editorial Sudamericana, Buenos Aires, Argentina. 405 pp.

CONTRERAS J, E FLORES, I HERRERA, L MAZZEI, A RIVERA \& R ROMERO (1971) La población y la economía de Chiloé durante la colonia (15671826). Ediciones Universidad de Concepción, Concepción, Chile. 49 pp.

COROMINAS J (1976) Diccionario crítico etimológico de la Lengua Castellana. IV volúmenes. Editorial Gredos, Madrid, España. 1117 pp.

CUNILL P (1970) Factores en la destrucción del paisaje chileno: recolección, caza y tala coloniales. Informaciones Geográficas (número especial): 235-264.

CUNILL P (1971) Chile meridional criollo: su geografía humana en 1700. Cuadernos Geográficos del Sur (número único): 21-75.

CHONCHOL J (1994) Sistemas agrarios en América Latina, de la etapa prehispánica a la modernización conservadora. Fondo de Cultura Económica S.A., Santiago, Chile. 445 pp.

DILLEHAY T (1976) Observaciones y consideraciones sobre la prehistoria y la temprana época histórica de la región centro-sur. Estudios antropológicos sobre mapuches en Chile sur-central, Universidad Católica de Chile, Temuco, Chile. 48 pp.

DILLEHAY T (1990) Araucanía: presente y pasado. Editorial Andrés Bello, Santiago, Chile. 153 pp.

ELIZALDE R (1970) La sobrevivencia de Chile. El Escudo Impresores-Editores Ltda., Santiago, Chile. $492 \mathrm{pp}$.

FINSTERBUSCH C (1934) Las dalcas de Chiloé y los chilotes. Revista Chilena de Historia y Geografía 82: 412-433.

GAJARDO R (1994) La vegetación natural de Chile clasificación y distribución geográfica. Editorial Universitaria, Santiago, Chile. 165 pp.

GAY C (ed) (1853) Viaje del capitán Juan Ladrillero al descubrimiento del estrecho de Magallanes (1557) Historia Física y Política de Chile. Imprenta de E. Thunot y Cia., París. Francia, Tomo II: 55-98.

GAY C (1862) Historia física y política de Chile. Agricultura. Imprenta de E. Thunot y Cia., París, Francia, Volumen I. 487 pp.

GAY C (1865) Historia física y política de Chile. Agricultura. Imprenta de E. Thunot y Cia., París, Francia, Volumen II. 450 pp.

GONZÁLEZ DE AGÜEROS P (1988) Descripción historial de Chiloé (1791). Reedición facsimilar con un apéndice documental. Editorial Universitaria, Santiago, Chile. 427 pp.

GONZÁLEZ DE NÁJERA A (1971) "Desengaño y reparo de la guerra del Reino de Chile. Editorial Andrés Bello, Santiago, Chile. 317 pp.

GUARDA G (1978) Historia urbana del Reino de Chile. Editorial Andrés Bello, Santiago, Chile. 509 pp. 
GUARDA G (1990) Flandes indiano. Las fortificaciones del reino de Chile (1541-1826). Ediciones de la Universidad Católica de Chile, Santiago, Chile. 425 pp.

GUEVARA T (1925) Historia de Chile. Chile Prehispano. Balcell \& Co., Santiago, Chile. Volumen II. 447 pp.

HEUSSER C (1994) Paleoindians and fire during de late Quaternary in southern South America. Revista Chilena de Historia Natural 67: 435-443.

LATCHAM R (1922) Los animales domésticos de la América Precolombina. Publicaciones del Museo de Etnología y Antropología, Santiago, Chile. 199 pp.

LATCHAM R (1936) La agricultura precolombina en Chile y los países vecinos. Ediciones de la Universidad de Chile, Santiago, Chile. 336 pp.

MALDONADO R (1897) Estudios geográficos é hidrográficos sobre Chiloé. Establecimiento Poligráfico "Roma", Santiago, Chile. 379 pp.

MASUDA S (1988) Algas y algueros en Chile. En: Masuda S (ed) Recursos naturales andinos: 265299. Universidad de Tokio, Tokio, Japón.

MEDINA J (ed) (1899) Primera información de servicios de Martín Ruiz de Gamboa. 6 de Abril de 1567. Colección de Documentos Inéditos para la Historia de Chile XIX: 229-243. Imprenta Elzeviriana, Santiago, Chile.

MEDINA J (1923a) Nota bibliográfica sobre el viaje de Enrique Brouwer a Chile. Colección de Historiadores de Chile XLV: 121-128. Imprenta Universitaria, Santiago, Chile.

MEDINA J (ed) (1923b) Narración histórica del viaje ejecutado del Este del estrecho de Le Maire a las costas de Chile, al mando de su excelencia el general Enrique Brouwer, en los años 1642 y 1643 . Colección de Historiadores de Chile XLV: 129-216. Imprenta Universitaria, Santiago, Chile.

MEDINA J (1952) Los aborígenes de Chile. Introducción de Carlos Keller, Imprenta Universitaria, Santiago, Chile. LXXII + 431 pp.

MOLINER M (1966) Diccionario de uso del español. Editorial Gredos S.A., Madrid, España, Volumen II. $1.585 \mathrm{pp}$

MORALEDA J (1888) Breve descripcion de la provincia de Chiloé, su poblacion, carácter de sus habitantes, producciones i comercio. San Cárlos de Chiloé, 20 de agosto de 1789. Esploraciones Jeográficas e Hidrográficas de José de Moraleda y Montero: 203228. Imprenta Nacional, Santiago, Chile.

MORENO P (2000) Climate, fire and vegetation between about 13,000 and $9,200{ }^{14} \mathrm{C}$ yr B.P. in the Chilean lake district. Quaternary Research 54: 81-89.

NIEMEYER H (2000) El escenario geográfico. En: Hidalgo J,V Schiappacasse, H Niemeyer F, C Aldunate del Solar \& I Solimano (eds) Culturas de Chile. Prehistoria desde sus orígenes hasta los albores de la conquista: 1-11. Editorial Andrés Bello, Santiago, Chile.

O’HIGGINS T (1942) Diario de viaje del capitán D. Tomás O’Higgins, de orden del virrey de Lima, el marqués de Osorno, 1796-1797. Revista Chilena de Historia y Geografía 101: 42-97.

OLGUÍN C (1970) Instituciones políticas y administrativas de Chiloé en el siglo XVIII. Editorial Jurídica de Chile, Santiago, Chile. 143 pp.

OYARZÚN A (1934) Cultura aborigen de Chiloé. Revista Chilena de Historia y Geografía 83: 235-254.

PACHECO A (1991) Una economía de conquista, Concepción siglo XVI. Revista de Historia, Universidad de Concepción (Chile) 1: 25-44.

PAGÉS A DE (sin fecha) Gran diccionario de la Lengua Castellana (de autoridades) con ejemplos de buenos escritores antiguos y modernos. Imprenta de Ángel Ortega, Barcelona, España, Volumen III. 870 pp.

PHILIPPI R (1885) Zoolojía. Sobre los animales introducidos en Chile desde su conquista por los españoles. Anales de la Universidad de Chile 67: 319-335.

PRIETO M \& C WUILLOUD (1986) Consecuencias ambientales derivadas de la instalación de los españoles en Mendoza en 1561. Cuadernos de Historia Regional, Universidad de Luján, Luján, Argentina. 35 pp.

PROMIS J (1991) Estrategias textuales en las cartas de Pedro de Valdivia al emperador Carlos V. En: Rojas-Mix M (ed) Cartas de Don Pedro de Valdivia que tratan del descubrimiento y conquista de la Nueva Extremadura: 257-263. Editorial Andrés Be1lo-Editorial Lumen S.A., Barcelona, España.

RAMÍREZ F (1996) Ecohistoria y destrucción en Chiloé continental: el Valle del Vodudahue 1700-1996. Bases históricas del desarrollo regional de Chile: 225 257. Universidad de Chile, Santiago, Chile.

REAL ACADEMIA ESPAÑOLA (1989) Diccionario de la Lengua Española. Editorial Espasa-Calpes S.A., Madrid, España. 1.416 pp.

RIBERA L (1897) Discurso que hace el alferez don Lázaro de Ribera, injeniero delineador, sobre la Provincia de Chiloé por órden del Supremo Gobierno de Lima, desde esta misma ciudad en agosto de 1782. En: Anrique N (ed) Cinco relaciones jeográficas e hidrográficas que interesan a Chile: 1-67. Imprenta Elzeviriana, Santiago, Chile.

ROBERTS N (1998) The Holocene and environmental history. Second edition. Blackwell Publishers Ltd., Oxford, United Kingdom. 316 pp.

RODRÍGUEZ J (1901) Revista de la Guerra de la Independencia de Chile. Colección de Historiadores y Documentos relativos a la Independencia de Chile. Imprenta Cervantes, Santiago, Chile. 395 pp.

SMITH R (1949) Datos estadísticos sobre el comercio de importación en el Perú en los años de 1698 y 1699. Revista Chilena de Historia y Geografía 113: 162177.

STEHBERG R (1980) Diccionario de Sitios Arqueológicos de Araucanía. Museo Nacional de Historia Natural, Publicación Ocasional (Chile) 31: 1-209.

THAYER OJEDA T (1913) Observaciones acerca del viaje de don García Hurtado de Mendoza a las provincias de los Coronados y Ancud. Revista Chilena de Historia y Geografía 11: 323-381.

TORREJÓN F (2001) Variables geohistóricas en la evolución del sistema económico pehuenche durante el periodo colonial. Revista Universum 16: 219-236.

TORREJÓN F \& M CISTERNAS (2002) Alteraciones del paisaje ecológico araucano por la asimilación mapuche de la agroganadería hispano-mediterránea (siglos XVI y XVII). Revista Chilena de Historia Natural 75: 729-736

URBINA R (1983) La periferia meridional indiana de Chiloé en el siglo XVIII. Ediciones Universitarias de Valparaíso, Valparaíso, Chile. 246 pp.

VIDAL GORMAZ F (1871) Esploracion de la costa de Llanquihue i archipiélago de Chiloé practicada por órden del supremo Gobierno por el capitan graduado de corbeta don Francisco Vidal Gormaz. Anales de la Universidad de Chile 39: 5-80.

VIDAL GORMAZ F (1875) Reconocimiento del rio Maullin por la comision esploradora de Chiloé i Llanquihue, bajo la dirección del capitan graduado de fragata. Anuario Hidrográfico de la Marina de Chile 1: 167-262.

VILLAGRÁN (1991) Historia de los bosques templados del sur de Chile durante el Tardiglacial y 
Postglacial. Revista Chilena de Historia Natural 64: 447-460.

VILLAGRÁN C, P MORENO \& R VILLA (1997) Antecedentes palinológicos acerca de la historia cuaternaria de los bosques chilenos. En: Armesto J, C Villagrán \& M Kalin (eds) Ecología de los bos- ques nativos de Chile: 51-69. Editorial Universitaria, Santiago, Chile.

ZAPATER H (1973) Los aborígenes chilenos a través de cronistas y viajeros. Editorial Andrés Bello, Santiago, Chile. $142 \mathrm{pp}$

Editor Asociado: Javier Figueroa

Recibido el 13 de abril de 2004; aceptado el 6 de septiembre de 2004 